\title{
PHOTON PBL: problem-based learning in photonics technology education
}

Nicholas Massa, Richard Audet, Judith Donnelly, Fenna Hanes, Marijke Kehrhahn

Nicholas Massa, Richard Audet, Judith Donnelly, Fenna Hanes, Marijke Kehrhahn, "PHOTON PBL: problem-based learning in photonics technology education," Proc. SPIE 9665, Tenth International Topical Meeting on

Education and Training in Optics and Photonics, 966514 (3 June 2007); doi: 10.1117/12.2207514

SPIE Event: Tenth International Topical Meeting on Education and Training in Optics and Photonics, 2007, Ottawa, Ontario, Canada 


\title{
PHOTON PBL: Problem-Based Learning in Photonics Technology Education
}

\author{
Nicholas Massa \\ Central Connecticut State University, 1615 Stanley Street, New Britain, CT 0605 \\ 860.832.3232, massanim@ccsu.edu \\ Richard Audet \\ Roger Williams University, One Old Ferry Road, Bristol, RI 02809 \\ 401.254.3357,raudet@rwu.edu \\ Judith Donnelly \\ Three Rivers Community College, 7 Mahan Drive, Norwich, CT 06030 \\ 860.885.2353,jdonnelly@trcc.ccommnet.edu \\ Fenna Hanes \\ New England Board of Higher Education, 45 Temple Place, Boston, MA 02111 \\ 617.357.9620,fhanes@nebhe.org \\ Marijke Kehrhahn \\ University of Connecticut, 249 Glenbrook Road, Storrs, CT 06269 \\ 860.486.0248, marijke.kehrhahn@uconn.edu
}

\begin{abstract}
Problem-based learning (PBL) is an educational approach whereby students learn course content by actively and collaboratively solving real-world problems presented in a context similar to that in which the learning is to be applied. Research shows that PBL improves student learning and retention, critical thinking and problem-solving skills, and the ability to skillfully apply knowledge to new situations - skills deemed critical to lifelong learning. Used extensively in medical education since the 1970's, and widely adopted in other fields including business, law, and education, PBL is emerging as an alternative to traditional lecture-based courses in engineering and technology education. In today's ever-changing global economy where photonics technicians are required to work productively in teams to solve complex problems across disciplines as well as cultures, PBL represents an exciting alternative to traditional lecture-based photonics education. In this paper we present the PHOTON PBL project, a National Science Foundation Advanced Technology Education (NSF-ATE) project aimed at creating, in partnership with the photonics industry and university research labs from across the US, a comprehensive series of multimedia-based PBL instructional resource materials and offering faculty professional development in the use of PBL in photonics technology education. Quantitative and qualitative research will be conducted on the effectiveness of PBL in photonics technician education.
\end{abstract}

\section{Introduction}

Photonics technicians are problem solvers - individuals who must skillfully apply their knowledge of lasers, optics, electronics, and related technologies in solving real-world problems [1]. Working side-by-side with engineers and scientists, photonics technicians are the "hands-on" side of an engineering team, responsible for designing experiments, building and troubleshooting prototypes, analyzing and interpreting data, and presenting experimental results to peers, supervisors and customers. Given the broad scope of duties required of the photonics technician it is ironic that photonics technician education programs are most often taught in a traditional instructor-centered manner that provides little opportunity for students to actively engage in real-world problem solving. This approach to education often results in graduates who do not have a full range of important employability skills and competencies needed in business and industry, such as the ability to: (1) apply their knowledge in new and novel situations, (2) communicate effectively, (3) work as members of an interdisciplinary team, and (4) engage in lifelong learning skills deemed critical by ABET EC2000 [2]. As a result, photonics technicians often enter the workforce inadequately prepared to adapt to the complex and ever-changing demands of the 21 st century high-tech workplace [3]. The PHOTON PBL project will address this challenge through the use of problem-based learning.

Tenth International Topical Meeting on Education and Training in Optics and Photonics, edited by Marc Nantel, Proc. of SPIE Vol. 9665, 966514 - () 2007 SPIE, OSA, IEEE, ICO doi: $10.1117 / 12.2207514$ 
In this paper we present the PHOTON PBL project, a National Science Foundation Advanced Technology Education (NSF-ATE) project aimed at creating a comprehensive series of multimedia-based PBL instructional modules or Challenges and providing faculty professional development in the pedagogy and use of PBL in photonics technology education. Developed in partnership with the photonics industry and university research labs from across the US, each PHOTON PBL Challenge will present a re-enactment of an authentic photonics problem encountered by a partner company or university. Unlike traditional case studies where students are just passive observers, the PHOTON PBL Challenges will actively engage students in the actual problem-solving process using an instructor facilitated multi-tier approach designed to scaffold the development of students' problem-solving and critical thinking skills. The PHOTON PBL Challenges are directly linked to the highly successful NSF-funded PHOTON2 curriculum and laboratory materials [1], which have been adopted at over 80 secondary and postsecondary institutions across the US. Quantitative and qualitative research will also be conducted on the effectiveness of PBL in photonics technician education.

\section{What is Problem-Based Learning?}

Problem-based learning is an instructional method that challenges students to "learn how to learn" by collaboratively solving genuine real-world problems. PBL is based on the constructivist model of learning, whose major tenets are (1) learning and understanding are directly related to the environment or context in which learning occurs, (2) cognitive conflict or "puzzlement" is the stimulus for learning and determines the organization and nature of what is learned, and (3) social environment is primary in providing alternative views and additional information against which we can test the viability of our understanding and comprehension. Research shows that compared to traditional lecture-based instruction, PBL improves student understanding and retention of ideas, critical thinking, communication and problem-solving skills, as well as the ability of students to adapt their learning to new situations - the cornerstone of lifelong learning $[4,5,6,7,8,9,10]$.

PBL teaches students the process of solving real-world, open-ended problems that may have a number of possible solutions. The pedagogical framework for the PHOTON PBL project is guided by Barrows' Model [8] originally developed at McMaster University in Canada for use in medical school education and subsequently adopted widely by medical, business, education, and engineering schools around the world. The Barrows Model involves a recursive problem-solving process that begins with a problem scenario presented in the context in which it is to be solved. Student teams work collaboratively in analyzing the problem by identifying relevant facts and learning issues, activating prior knowledge, generating hypotheses, reflecting on their beliefs about the problem, and generating learning objectives needed to solve the problem. This phase is followed by a period of self-directed learning whereby each student engages in learning specific content identified as relevant in the initial problem analysis phase. During this phase, the instructor serves as a consultant, guiding the student as they seek out required resources and providing additional information as needed, thus shifting the responsibility for learning onto the student. By shifting the responsibility for learning onto students and providing scaffolds for learning, students are more likely to develop the self-directed learning skills needed to successfully engage in lifelong learning [3]. Upon completion of the self-directed learning phase, students reconvene to assess and evaluate their problem solution based on their new understanding of the problem, and reformulate solutions if needed. This process, illustrated in Figure 1, may repeat itself several times in the process of solving a single problem. Student evaluation in PBL may take one of several forms, from a final patient diagnosis in medical education [8], to the generation and presentation of a formal proposal including cost/benefit analysis and/or feasibility analysis in an engineering education application [11]. In either case, the final problem solution takes the form of what would be most appropriate in that particular context.

While PBL has been used extensively in medical education since the early 1970's and has been widely adopted in other fields including business, law, and education, it is only beginning to emerge as an alternative to the traditional lecture-based approach to engineering and technology education [5,6,7]. For example, Nashville State Technical College has adopted PBL in its two-year engineering technology program through its NSF-funded CaseFiles ${ }^{\circledR}$ project [10]. Four-year engineering institutions such as University of Buffalo, University of Delaware, Worcester Polytechnic Institute, and several others have also adopted PBL in selected engineering courses, reporting increases in problem-solving skills, critical thinking, retention, and motivation for learning $[11,12,13]$. Given the practical nature of photonics technology education where students must learn to apply their knowledge in solving complex, real-world problems, PBL appears well-suited for educating technicians capable of addressing the everchanging needs of today's technological and multicultural society. 


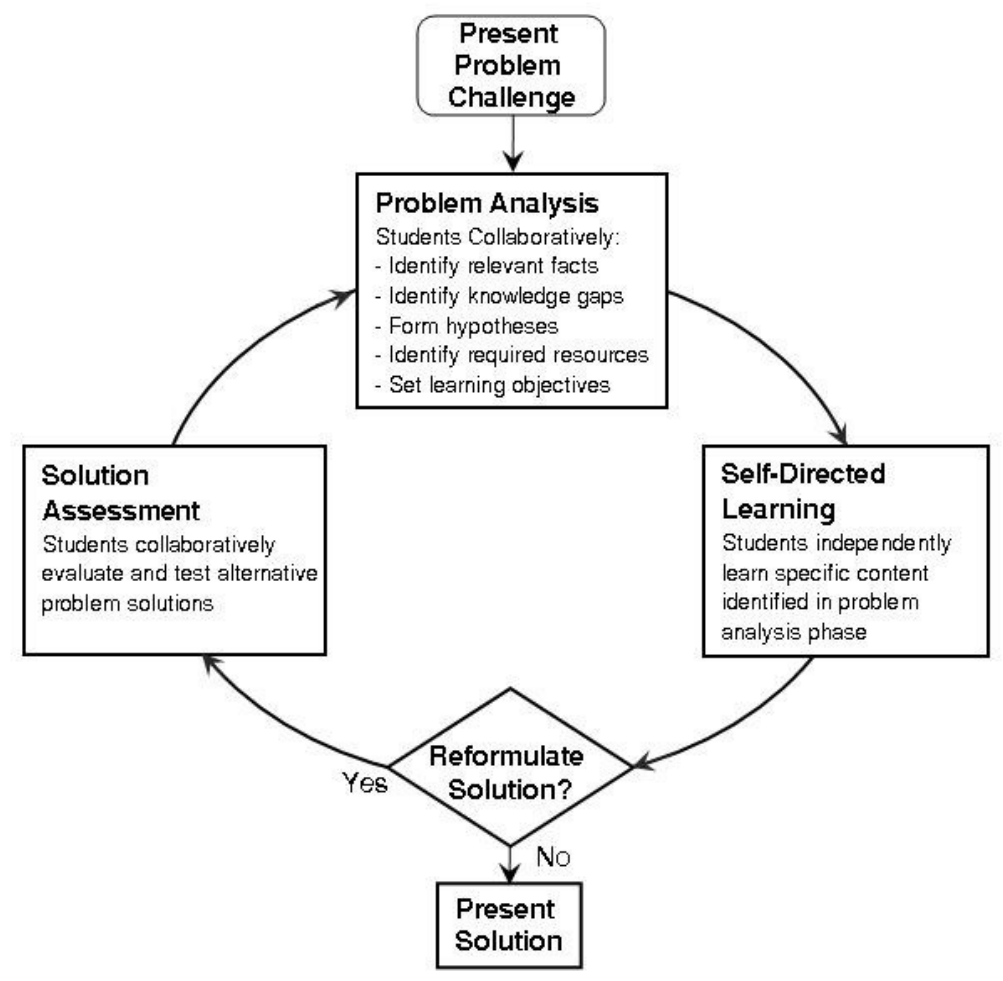

Figure 1. The PBL Process

\section{The PHOTON PBL Project}

The main obstacles for educators in adopting PBL in technology education are the overall lack of instructional resources and faculty training in the use of PBL in the classroom. This is especially true in the field of photonics, where limited instructional resources have always been an issue for educators. These instructional resources include genuine real-world problems linked to course content, problem-solving strategies, assessment and evaluation methods, alternative problem solutions, supplementary online resources, and other relevant information needed to help educators implement PBL in their curricula. The main purpose of these instructional resources is to help faculty create a learning environment that emulates the context in which students must ultimately apply their knowledge the workplace. Research shows that solving genuine problems is more likely to engage and motivate learners [14]. This is a major departure from traditional "end-of-chapter" problems whose parameters are well-defined and solutions artificial. PBL instructional materials must effectively guide students through the problem solving process, requiring that students not only properly frame the problem, but also identify knowledge gaps, set learning goals, and seek out the resources needed to converge on a solution, both individually and collaboratively. This process is vital in developing the metacognitive skills needed for lifelong learning $[1,3,15]$.

\subsection{PHOTON PBL Instructional Resource Development}

To address the lack of instructional resources for PBL in photonics technology education, the PHOTON PBL project, in partnership with selected photonics industry partners and university research laboratories from across the US, will create a series of eight multimedia PBL Challenges (DVD) and instructional resource materials covering a broad range of photonics applications. Active participation of industry and university partners in providing genuine real-world photonics problems that can be used in the classroom, actual problems whose solutions have been documented and tested, serves as the centerpiece of the PHOTON PBL project. Unlike traditional case studies in which students passively study and critique problem situations encountered by others, the PHOTON PBL Challenges are designed to actively engage students in the problem-solving process by virtually "inserting" them into the context and environment in which the problem is to be solved, thus emulating the actual workplace experience. 
For each PHOTON PBL Challenge, both a student version and an instructor version will be developed. The student version will contain a multimedia introduction to the specific company or university research lab to set the context for the problem challenge followed by a re-enactment of the problem statement by actual industry/university personnel, the problem-solving process engaged in by actual engineers and technicians, and a detailed presentation of the problem solution. A problem solving "toolbox" will be incorporated into each PHOTON PBL Challenge to provide students with the learning resources needed to successfully guide them through the problem-solving process. The instructor version will contain all of the information contained in the student version plus additional instructional resources including an instructor's "toolbox" containing instructional strategies, assessment and evaluation tools, industry standards related to the problem challenge, a solution guide detailing alternative problem solutions, and information regarding alignment with national science, math, language arts and technological literacy standards. The instructor version will also contain a generic PBL template and instructions to help them develop their own PBL Challenges.

Each PHOTON PBL Challenge is directly linked to the highly successful NSF-funded PHOTON curriculum and laboratory materials [1], which are aligned with national science, math, language arts and technological literacy standards, and have been adopted at over 80 secondary and post secondary institutions across the US. These fieldtested instructional materials and laboratory equipment have been developed to support instruction in topics including geometric and wave optics, laser principles and applications, fiber optics, lighting and illumination, environmental sensing, laser materials processing, optical fabrication and testing, and biophotonics. Each PHOTON PBL Challenge is designed to be completed by students in a one- to four-week time frame and can be customized by the instructor for complexity allowing for multiple problems to be presented within a typical 15 -week semester.

Another obstacle in adopting PBL in technology education is its departure from traditional didactic methods. A common complaint among students introduced to PBL for the first time is the stress and anxiety associated with open-ended problems and self-directed learning. Most students are accustomed to traditional lecture-based methods of instruction in which information is passively "transferred" from the instructor to the student in an environment that is well structured and where problem parameters are clearly defined and closed-ended. Conversely, "The sudden propulsion to the uncertain, self-directed technique and the responsibility associated with PBL exposes learners to an uncertain and unknown dimension, thus, eliciting fear, anxiety, and the desire to hold on to something familiar when the outcome is unknown [9]." This frustration and anxiety can not only lead to disengagement from the learning process among students, but can also create a stressful situation for faculty trying to transition to PBL from more traditional instructional methods. To ease this transition, the PHOTON PBL Challenges are designed to be implemented using three levels of structure ranging from Level 1 (Instructor Led - Highly Structured), to Level 2 (Instructor Guided - Moderately Structured), to Level 3 (Instructor as Consultant - Open-Ended) depending on the technical nature of the problem and the ability level of the students. By providing scaffolds for learning that allow students (and faculty) to progress through the PBL Challenges along a continuum, from a low autonomy mode (structured) to high autonomy mode (open-ended) over time, faculty will be more likely to adopt this new mode of instruction and students more likely to develop the skills and confidence needed to take responsibility for their own learning $[16,17,18,19]$. This is illustrated in Figure 2 and described in the proceeding sections.

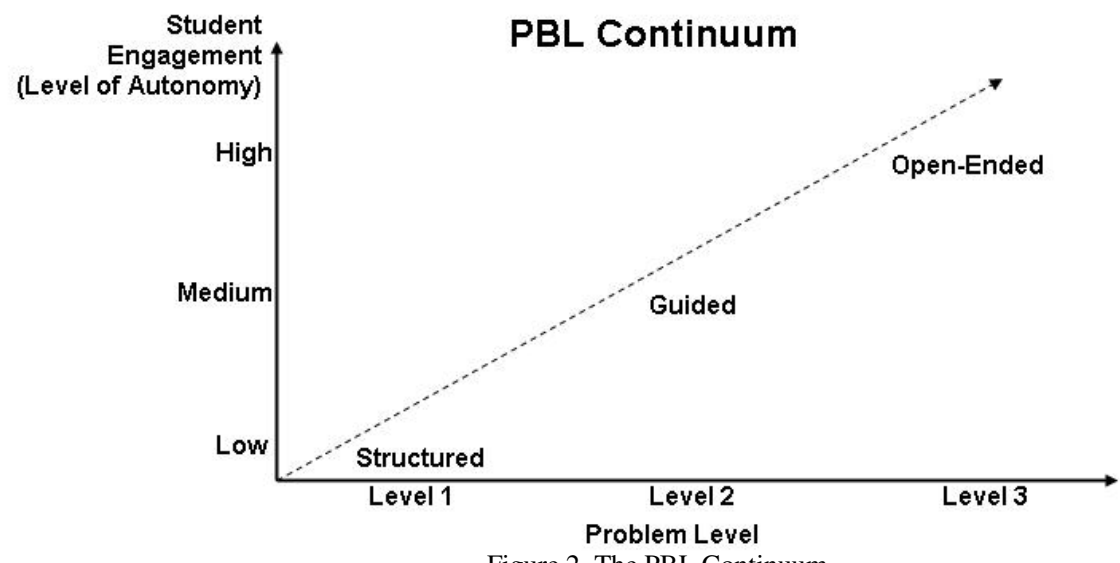

Figure 2. The PBL Continuum 


\subsubsection{Level 1 (Instructor Led - Structured)}

In Level 1, students are presented with the PBL challenge in its entirety as a multimedia-based case study. This includes a multimedia introduction to the environment (industry/university research lab tour) in which the context of the particular photonics application is presented, a re-enactment of the problem statement, group problem analysis and discussion, and problem solution recorded at the industry/university partner site. The purpose of Level 1 is to introduce the student to the concepts, principles, and procedures associated with problem-based learning. In Level 1, the instructor guides the student through each phase of the problem-solving process in a highly structured format which includes defining and framing the problem, identifying resources needed to solve the problem, generating possible problem solutions, testing hypotheses, and converging on an optimal solution as a team effort. During the presentation of the PBL Challenge, the instructor has the option of pausing the multimedia presentation at specific points to encourage student discussion of the problem-solving process, technical content, and other situational factors and constraints that must be taken into consideration in the solution of the problem. This active learning strategy will help develop students' ability and confidence to engage in the problem-solving process as well as critical thinking and metacognitive skills $[1,3]$.

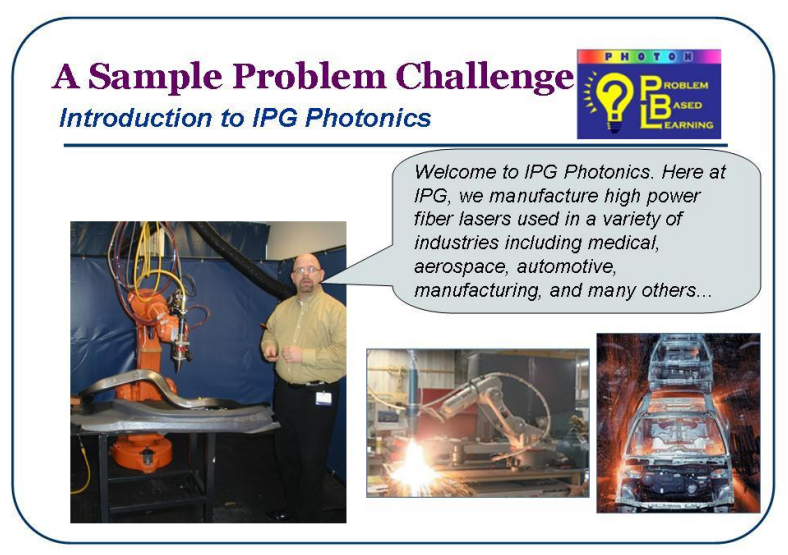

(a)

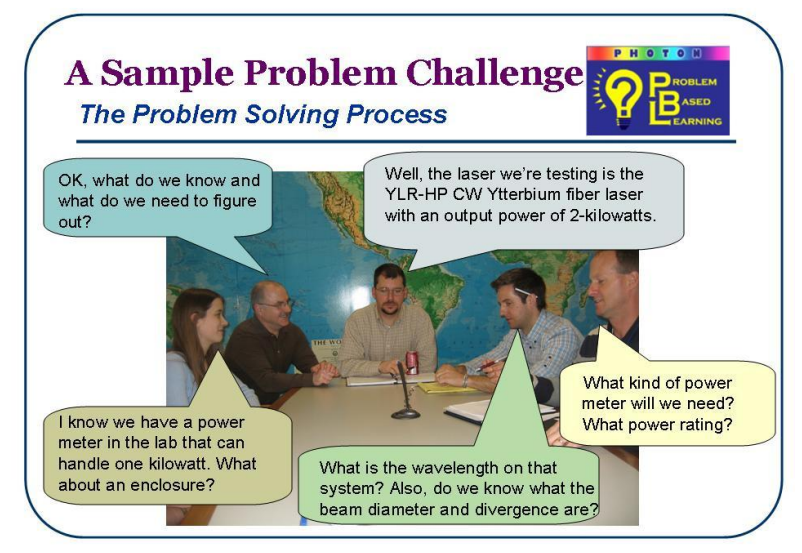

(c)

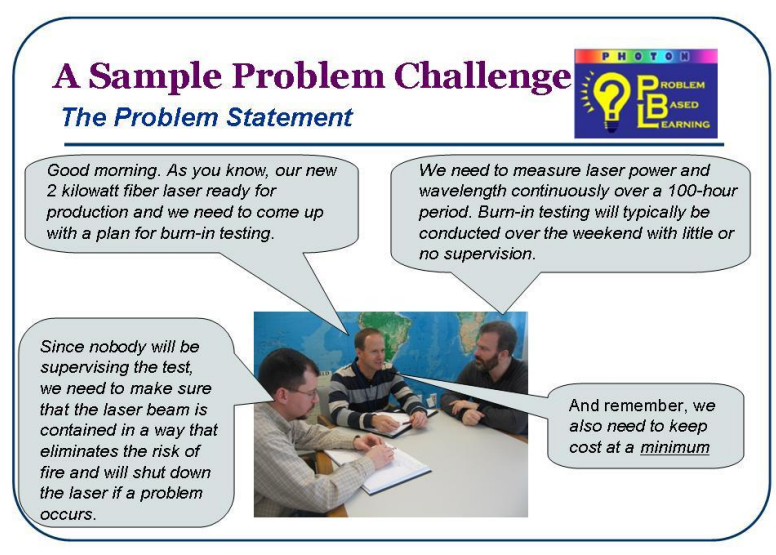

(b)

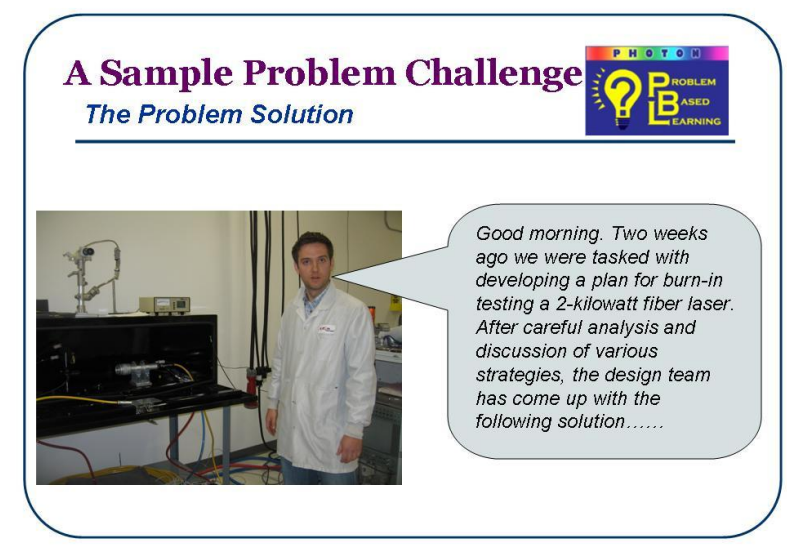

(d)

Figure 3. Graphical Representation of a PHOTON PBL Challenge created in partnership with IPG Photonics, Oxford, MA: (a) Scene 1: The Introduction - Presented in Levels 1, 2 \& 3. (b) Scene 2: The Problem Statement - Presented in Levels 1, 2 \& 3. (c) Scene 3: The Problem Solving Process - Presented in Levels $1 \& 2$ initially; Level 3 only at the end of the Challenge. (d) Scene 4: The Problem Solution - Presented initially in Level 1 only; Presented in Levels $2 \& 3$ at the end of the Challenge

\subsubsection{Level 2 (Guided)}

In Level 2, students have been exposed to the overall problem-solving process through Level 1 and have begun to develop their own problem-solving skills. As in Level 1, students are presented with the multimedia-based 
introduction, re-enactment of the problem statement, group problem analysis and discussion to guide the problemsolving process (Scenes 1-3), but the solution is held back until the end. Working in small teams, students use the information provided to seek the resources needed to solve the problem and generate possible solutions. During this phase the instructor acts as a guide or facilitator to ensure that students stay on track, but refrains from providing solutions or answers to specific questions. This strategy is intended to further develop students' ability to think critically by allowing them to "get dirty and make mistakes," but at the same time providing a safety net so that learning occurs without risk of failure. After converging on and presenting their own solution to the problem, students are presented with the industry/university partner solution and a subsequent group reflection activity is conducted to compare and contrast results.

\subsubsection{Level 3 (Open-Ended)}

In Level 3, students are presented with the most realistic representation of the problem statement as it would be encountered in the "real world" - a true problem-based learning challenge. Students are provided only with information from Scenes 1 and 2, and are required to formulate their own solutions as part of a mock design team. Drawing from the problem-solving knowledge and skills acquired through engagement with Level 1 and Level 2 Challenges, students engage in the problem-solving process by defining and framing the problem, identifying resources needed to solve the problem, generating and testing alternative solutions, and converging on the most appropriate solution for the given context. During this process the instructor acts as a consultant, providing hints or clues on request, but for a price (e.g., points deducted from a mock budget). Only after the solution has been presented by the student design teams in a formal presentation in a simulated design review is the actual industry/university problem-solving process and solution revealed. Student processes and solutions are then reviewed and critiqued against that of the industry/university partner and recommendations for improvements are discussed.

\subsection{Professional Development in Problem Based Learning}

Just as important as the lack of instructional resources and materials for PBL in photonics technology education is the lack of pedagogical knowledge among technology educators needed to teach PBL. This is common in technology education. While great progress has been made over the past decade in upgrading the technical skills of technology faculty through professional development programs sponsored by NSF and other funding organizations, less attention has been given to the instructional methods used to teach these skills to students. The old adage "teachers teach the way they were taught" still rings true [20]. Technology educators are typically highly trained experts in a very specific technical field. Unfortunately, most have had little or no formal training in education and pedagogy [21]. Like their predecessors, technology educators most often employ an instructor-centered approach in their teaching, attempting to "fill" the student with knowledge rather than assisting the student in developing the capacity to learn. If PBL is to be successfully adopted, technology educators must be provided with professional development designed to introduce them to the pedagogical underpinnings of PBL, in a way that changes their way of thinking about teaching and learning as well as their practice: the design, evaluation, and delivery of instruction. They must learn how to effectively integrate content and pedagogy in a way that actively engages students in individual and collaborative problem-solving, analysis, synthesis, critical thinking, reasoning, and skillfully applying knowledge in real-world situations [22,23].

Researchers [24] argue that for professional development to be effective, it must extend beyond the typical oneor two-day workshops, which overall have been shown to be ineffective in producing changes in teacher practice. In fact, research on the effectiveness of professional development efforts aimed at producing changes in practice show that only about 15 percent of what is learned in classroom settings is ever applied on the job because these efforts are usually short-term, lack continuity through adequate follow-up and ongoing feedback from experts, are isolated from the participants' classrooms and school contexts, take a passive approach to training teachers, and allow little opportunity to learn by doing and by reflecting with colleagues [25,26]. In one example, Saylor and Kehrhahn [27] found that compared to the typical 10-20 percent transfer of knowledge rate typical of short-term workshop models, the continuous nature of a yearlong professional development program with middle school teachers resulted in an 80 percent transfer of knowledge to the classroom.

The PHOTON PBL project will address the need for change in instructional practice by providing high school and community college technology educators from across the US continuous professional development in the principles and applications of PBL over a two-year period. By involving instructors directly in the PBL Challenge 
development process, providing ongoing instruction, support and feedback, and time for collaboration with colleagues and mentors in the implementation of PBL in their classrooms, they will build the capacity to develop their own PBL challenges in other courses. In its first year, the PHOTON PBL project has recruited 16 seasoned technology educators ( 8 high school; 8 college level) trained in the use of the PHOTON curriculum and laboratory materials to be part of the PHOTON PBL Challenge development team. These educators will experience PBL firsthand by working with the PHOTON PBL Project team in developing and alpha testing the first four prototype PBL challenges in their classes. Working through the PBL cycle, instructors will use the development and implementation of the PHOTON PBL Challenges as an actual problem-solving activity - using PBL to teach PBL. Through this process, the instructors will evaluate, update and refine the PHOTON PBL challenges in preparation for alpha testing a second group of four additional PHOTON PBL challenges to be developed during year two of the project. Instructors will be provided with ongoing mentoring and support throughout the duration of the project through online collaboration, site visits, and periodic meetings. Photonics industry and PBL experts from across the US will serve as mentors to the instructors through a dedicated list server. In all, eight PHOTON PBL Challenges will be tested by 16 instructors using the using the PBL process. An additional outcome of this effort will be the development of a teacher's guide to PBL, developed for teachers by teachers.

\subsection{Research in Problem-Based Learning}

While PBL has been used successfully in the medical profession for decades with great acclaim, less is known about the effectiveness of PBL in engineering, and especially in technician education. A review of the literature on PBL identified several studies conducted to validate the efficacy of PBL in engineering education with researchers reporting mixed results. For example, in a study conducted at Maastricht University [6], researchers found that PBL was more effective in the first years of an engineering program, but only when integrated with some directive instruction. In another study conducted at South Dakota School of Mines [5], researchers examined the effectiveness of PBL as an alternative to traditional instructional methods in the freshman year of engineering. Overall they found that students in the experimental cohort (PBL) performed better academically, had a higher retention rate, and were generally more satisfied than those students in the control group, which used a traditional lecture approach. In another study in which researchers examined the effects of PBL on self-regulated learning, results revealed that PBL students had higher levels of intrinsic goal orientation, task value, use of elaborative learning strategies, critical thinking, metacognitive self-regulation, and peer learning compared to control group students (traditional instruction) [28]. Conversely, in a review of the literature on PBL, researchers found that while evidence suggests that students in PBL have a more positive attitude and are more likely to take responsibility for their own learning, PBL requires time and effort in gaining acceptance and that more effort is needed in developing skill in facilitation and attitude toward self-directed learning [9]. In an effort to resolve these and other variations in the reported effectiveness of PBL as compared to traditional lecture-based instructional methods, researchers at Middlesex University [29] conducted a meta-analysis involving 91 citations. The results of the meta-analysis showed that variations in instructional methods, implementation, and assessment of learning outcomes yielded inconclusive evidence upon which to provide robust answers to the questions about the effectiveness of PBL. The researchers concluded that while PBL appears to be a promising alternative to traditional lecture-based methods of instruction in engineering and technology education, more research is needed to assess its efficacy.

To address the need for more research on PBL in technology education, the PHOTON PBL project will work in partnership with researchers from the University of Connecticut NEAG School of Education to conduct quantitative and qualitative research on the effectiveness of PBL as compared to traditional lecture-based methods with regard to learning outcomes, problem-solving and critical thinking skills, metacognitive development, self-efficacy, and motivation. Researchers will also examine the extent to which specific professional development activities contribute to changes in teaching practices (i.e., transfer of training) among participating faculty. Data sources will include instructor and student questionnaires, classroom observations, personal interviews, anecdotal data, documents and other artifacts. The research will result in a series of published articles and may also provide a basis for doctoral research for project participants pursuing graduate degrees in education at the University of Connecticut. 


\section{Conclusion}

PBL has been shown to be an effective educational approach that improves student learning and retention, critical thinking and problem-solving skills, and the ability to skillfully apply knowledge to new situations - skills deemed critical to lifelong learning. In today's ever-changing global economy where photonics technicians are required to work productively in teams to solve complex problems across disciplines as well as cultures, PBL represents an exciting alternative to traditional lecture-based photonics education.

In this paper we presented an introduction to the PHOTON PBL project, a three-year National Science Foundation Advanced Technology Education (NSF-ATE) project aimed at creating, in partnership with the photonics industry and university research labs from across the US, a comprehensive series of multimedia-based PBL instructional resource materials and offering faculty professional development in the use of PBL in photonics technology education. Over the three-year period that began in Fall 2006, the PHOTON PBL project will: (1) create eight multimedia PBL Challenges (DVD) and instructional resource materials covering a broad range of photonics applications, (2) train 16 high school and community college technology educators from across the US in the use of PBL for photonics technology education, (3) conduct quantitative and qualitative research on the effectiveness of PBL in photonics technician education, and (4) disseminate the multimedia PBL instructional materials and research findings through a dedicated website, peer-reviewed educational journals and conference presentations to inform engineering education pedagogy.

\section{Acknowledgements}

PHOTON Problem Based Learning (PBL): A Photonics Professional Development Project

Funded in part by the Advanced Technological Education program of the National Science Foundation (ATE 0603143). Project Principal Investigator, Fenna Hanes, New England Board of Higher Education; Co-principal Investigators, Judy Donnelly, Three Rivers Community College; Dr. Nicholas Massa, Central Connecticut State University; Dr. Marijke Kehrhahn, University of Connecticut; Dr. Richard Audet, Roger Williams University. Website: $\underline{\text { http://www.nebhe.org/index.php?option=com_content\&task=view\&id=201\&Itemid=175. }}$

Project PHOTON2: Web-based Collaborative Learning for Teachers

Funded in part by the Advanced Technological Education program of the National Science Foundation (ATE 0302528). Principal Investigator, Fenna Hanes (Project Manager), New England Board of Higher Education; CoPrinciple Investigators, Judith Donnelly, Three Rivers Community College; Marijke Kehrhahn, Neag School of Education (University of Connecticut); Nicholas Massa and Barbara Washburn, both Springfield Technical Community College

Project PHOTON: A Curriculum Development, Teacher Enhancement and Laboratory Development Project

Funded in part by the Advanced Technological Education program of the National Science Foundation (ATE 0053284). Principal Investigator, Judith Donnelly, Three Rivers Community College; Co-Principal Investigators Fenna Hanes (Project Manager), New England Board of Higher Education; John Swienton, Exfo USA, Inc.; Senior Personnel Nicholas Massa and Barbara Washburn, both Springfield Technical Community College

The authors wish to thank Dr. James Johnson (The CaseFiles ${ }^{\circledR}$ Project) of Nashville State Community College in Nashville, Tennessee and his invaluable contributions and support to the PHOTON PBL project.

\section{References}

1. Massa, N. M., Kehrhahn, M., Donnelly, J., Hanes, F., \& Washburn, B. A., "PHOTON2: A Web-Based Professional Development Model for Photonics Technology Education”, Proceedings of the SPIE Annual Conference, Ottawa, Canada, September (2004).

2. Engineering Criteria 2000: Criteria for Accrediting Engineering Technology Programs. Published by The Accreditation Board for Engineering and Technology (ABET), Baltimore, Maryland. http://www.abet.org/images/Criteria/T001\%200506\%20TAC\%20Criteria\%2011-29-04.pdf; (2004)

3. Massa, N. M., Masciadrelli, G. J., \& Mullett, G. J., "Re-Engineering Engineering Technician Education for the New Millennium", Proceedings of the ASEE Annual Conference, Portland Oregon, June (2005).

4. Savery, J. R., \& Duffey, T. M., "Problem based learning: An instructional model and its constructivist framework", In B. G. Wilson (Ed.), Constructivist learning environments: Case studies in instructional design, Englewood Cliffs, NJ: Educational Technology Publications, (1996).

5. J.J. Kellar, W. Hovey, M. Langerman, S. Howard. L. Stetler, H. Heilhecker, L. Arneson-Meyer and S. Kellogg, "A Problem Based Learning Approach for Freshmen Engineering," Conference Proceedings Session F2G, Frontiers in Education 2000, Kansas City, MO, October, (2000).

6. Perrenet, J.C., Bouhuijs, P.A.J., \& Smits, J.G.M.M, "The Suitability of Problem-based Learning for Engineering Education: Theory And Practice", Teaching in Higher Education, 5, 3, (2000) pp. 345-358.

7. Forrester, V. \& Chau, J., "Current Developments in problem based learning within the Hong Kong Institute of Education", In J. Marsh (Ed.) Implementing Problem Based Learning Project: Proceedings of the First Asia Pacific Conference on Problem Based Learning (pp.201-208). Hong Kong: The University Grants Committee of Hong Kong, Teaching Development Project (1999).

8. Barrow, H.S., "A Taxonomy of Problem Based Learning Methods”, Medical Education, 20 (1986), pp 481-486. 
9. Zubaidah, S., "Problem-Based Learning: Literature Review", Singapore Nursing Journal, 32 (4), Ocober-December (2005), pp 50-54.

10. http://www.thecasefiles.org

11. Cheville, Allen, Case Teaching Notes for "The Zoom Lens: A Case Study in Geometrical Optics" Department of Electrical Engineering Oklahoma State University. Available online at: http://ublib.buffalo.edu/libraries/projects/cases/zoom_lens/zoom_lens_notes.html

12. http://www.udel.edu/pbl/

13. American Association of Colleges and Universities (AAC\&U) Newsletter, "Worchester Polytechnic Institute's Project-Based Curriculum Sets High Standards and Connects Science and Technology with Humanities and Social Sciences", September (2001). Available online at: http://www.aacu-edu.org/aacu_news/AACUNews01/September01/feature.htm

14. Keeton, M. T., Sheckley, B. G., \& Griggs, J. K., Effectiveness and Efficiency in Higher Education for Adults, Published by the Council for Adult and Experiential Learning (CAEL), Chicago (2002).

15. Bransford, J. D., Donovan, M. S., Pellegrino, J. W., (Eds.), How People Learn, Washington, DC: National Academy Press (1999).

16. Massa, N. M., "Metacognition and Persistence in Web-Based Courses," Doctoral Dissertation, University of Connecticut, Storrs, CT (2003).

17. Cennamo, K. S., Ross, J. D., \& Rogers, C. S., "Evolution of a Web-Based Course: Incorporating Strategies for Self-Regulation,” Educause Quarterly, 25, 1(2002) pp.28-33.

18. Grow, G. O., "Teaching Learners to be Self-Directed." Adult Education Quarterly, 41 3(1991), pp.125-149.

19. McLaughlin, M. W., \& Oberman, I., Teacher Learning: New Policies, New Practices, Teachers College Press, New York (1996)

20. Collins, A., \& Hastings, J., "Teaching teachers practice what you teach", Science and Children, 27 (1990), pp. 38-39.

21. Wankat, P. C., "Educating engineering professors in education", Journal of Engineering Education, October (1991), pp. 471-475.

22. F.P. Deek, F.P., Kimmel, H., \& McHugh, J., "Pedagogical changes in the delivery of the first course in computer science: Problem solving then programming", Journal of Engineering Education, 87, 3 (July 1998), pp. 313-320.

23. Meier, R.L., Williams, M.R., and Humphreys, M.A., "Refocusing our efforts: assessing non-technical competency gaps", Journal of Engineering Education, 893 (2000), pp. 377-385.

24. Loucks-Horsley, S., Hewson, P. W., Love, N., Stiles, K. E., Designing Professional Development For Teachers Of Science And Mathematics, Corwin Press, Thousand Oaks (1998).

25. Ford, J. K., \& Weissbein, D. A., "Transfer of training: An updated review and analysis", Performance Improvement Quarterly, 10 2(1997), pp. 22-41.

26. National Center for Education Statistics, Digest of Education Statistics (NCES), U.S. Department of Education, Washington, D.C. (1999), pp. 21-22

27. Saylor, P. R., \& Kehrhahn, M. T., "The influence of the implementation of a transfer management intervention on transfer of training", In O.A. Aliaga (Ed.) AHRD Conference Proceedings, Baton Rouge, (2001).

28. Sunger, S., Tekkaya, C., "Effects of Problem-Based Learning and Traditional Instruction on Self-Regulated Learning", The Journal of Educational Research, 99 5(May/June 2006).

29. Newman M., "A pilot systematic review and meta-analysis on the effectiveness of problem-based learning", On behalf of the Campbell Collaboration Systematic Review Group on the Effectiveness of Problem-based Learning, Newcastle upon Tyne, UK: Learning and Teaching Support Network-01, University of Newcastle upon Tyne, (2003). Available online at: http://www.hebes.mdx.ac.uk/teaching/Research/PEPBL/PSR-PBL.pdf 